American Journal of Infectious Diseases 1 (2): 86-88, 2005

ISSN 1553-6203

(C) 2005 Science Publications

\title{
ERCP Related Sepsis
}

\author{
Iffet Palabıyıkoglu, Emin Tekelı, Derya Aysev, Mustafa Sırlak, Sibel Kaymakcı and Sultan Ozturk \\ Infection Control Committee of Medical Faculty of Ankara University, Ankara, Turkey
}

\begin{abstract}
Endoscopic procedures performed worldwide have increased considerably in recent years. In addition to diagnosis, many cases previously necessitating surgery now often can be carried out by endoscopic techniques. However, endoscopy has introduced its own infection risk. Most reports of gastrointestinal endoscopy-associated infection describe sepsis after endoscopic retrograde cholangiopancreatography (ERCP) in patients with biliary tract obstruction. During this study, which was conducted by Infection Control Committee of Ankara University Hospital, 13 out of 1147 (1.1\%) and 17 out of 922 patients (1.8\%) had ERCP related sepsis in 2002 and 2003 respectively, at the ERCP Unit of Gastroenterology Department. Sepsis-caused mortality were 23.1 and 29.4\% in 2002 and 2003 respectively. The first four causative agents were Escherichia coli, Pseudomonas spp, Klebsiella spp and Enterobacter spp. Type and frequency of the causative agents remind that both endogenous and exogenous mechanisms are together responsible for the infections emerging from ERCP Unit. Besides, increasing isolation of Pseudomonas spp. brings out the strong need for re-evaluation of infection control measures, mainly effective cleansing and disinfection of endoscopes.
\end{abstract}

Key words: Endoscopy and infection, disinfection of endoscopes, infectious complications of ERCP

\section{INTRODUCTION}

The considerable increase in endoscopic procedures performed worldwide in recent years has also introduced serious infection control issues. Endoscopic retrograde cholangio-pancreatography (ERCP) is the most risky diagnostic and therapeutic gastrointestinal endoscopic procedure. As techniques develope, endoscopes and accessories become more complicated, resulting in augmentation of problems concerning cleansing and disinfection of the equipment $^{1-3]}$. Unfortunately, there are no studies analyzing the individual data about ERCP related infections of several ERCP units in Turkey. The aims of this study are to assess the patients having ERCP related sepsis after the procedure during the hospitalization period in Gastroenterology Department of Ankara University Hospital, also concerning the causative agents and to re-evaluate infection control measures in the light of the findings.

\section{MATERIALS AND METHODS}

One-thousand one hundred and forty-seven and 922 procedures have been performed in ERCP Unit of Gastroenterology Department of Ankara University Hospital during 2002 and 2003 respectively. Patients hospitalized in the same institution were observed for hospital infection.

It's known that, sepsis occurring 48-72 hours after admittance to the hospital or after any procedure is accepted nosocomial ${ }^{[4,5]}$. Diagnosis of ERCP related sepsis was based on this fact.
Microbiological analysis were fulfilled in Central Bacteriology Laboratory at the campus and isolated microorganisms were identified by using standard methods ${ }^{[6]}$.

\section{RESULTS}

During this study which was conducted by Infection Control Committee of Ankara University Hospital, 13 out of 1147 (1.1\%) and 17 out of 922 patients $(1.8 \%)$ had ERCP related sepsis in 2002 and 2003 respectively, at the ERCP Unit of Gastroenterology Department.

Individuals diagnosed ERCP related sepsis (having no other infection) were recorded as a subgroup of primary bacteremia in the surveillance.

Causative agents are listed in the Table 1. As two patients in 2002 had polimicrobial bacteremia, total number of isolation is 15 .

Three patients in 2002 and 5 patients in 2003 died because of serious infections. That is, mortality rates arousing from ERCP related sepsis were $23.1 \%$ in 2002 and $29.4 \%$ in 2003.

\section{DISCUSSION}

Surveillance of the subjects undergoing endoscopy is important in order to disclose the risk of infection. However, out-patient-basis of the procedure and long incubation period of certain infections (hepatitis B and tuberculosis), creates difficulties in follow-up and causal relationship, resulting in underestimate of real

Corresponding Author: Assoc. Prof. Iffet Palabiyıkoglu, Infection Control Committee of Medical Faculty of Ankara University, 06100 Samanpazarı / Ankara, Turkey 
Am. J. Infectious Dis., 1 (2): 86-88, 2005

Table 1: Distribution of causative microorganisms

\begin{tabular}{lccc}
\hline Causative microorganisms & Patients (n) - 2002 & Patients (n) - 2003 & Total \\
\hline Escherichia coli & 4 & 7 & 11 \\
Pseudomonas spp. & 1 & 4 & 5 \\
Klebsiella and Enterobacter spp. & 2 & 3 & 5 \\
Methicillin resistant S. aureus & 3 & 1 & 4 \\
Enterococcus spp. & 3 & 1 & 4 \\
Coagulase negative staphylococci & 1 & 0 & 2 \\
Stenotrophomonas maltophilia & 1 & 1 & 1 \\
\hline
\end{tabular}

proportion of several infections. Bacterial infections with swift and dramatic outcome (such as ERCP related sepsis) are diagnosed easily and more, but large trials concerning ERCP related infections are limited. A study indicated that 9 of 179 patients (5.2\%) had sepsis, bacteremia mostly accompanying therapeutic procedures and bile duct obstruction ${ }^{[7]}$.

Another trial consisting 2010 individuals undergoing ERCP indicated that $51(2.5 \%)$ of them had sepsis. Pseudomonas aeruginosa being the most isolated agent. Alveyn ${ }^{[8]}$ concluded that the wide range of sepsis complicating ERCP (between 0.16\%-16\%) was a result of different sampling and culturing methods ${ }^{[9]}$.

In this study, 13 out of $1147(1.1 \%)$ and 17 out of 922 (1.8\%) patients undergoing ERCP during 2002 and 2003 respectively in Gastroenterology Section of Ankara University had ERCP related sepsis.

Endoscopy / ERCP related infections may be endogenous and may exogenously spread through improperly cleansed or disinfected endoscopes as well. Endogenous source is the intestinal flora and generally Escherichia coli and Enterococci are isolated. Bacteria that can easily proliferate in moist, such as Pseudomonas, Klebsiella and Enterobacter species, are frequently the causal agent of exogenous infections ${ }^{[1-}$ ${ }^{4,10,11]}$. As shown in the Table 1, dissemination of the agents points at both exogenous and endogenous mechanisms. On the other hand, increase in the isolation of Pseudomonas species reminds to concentrate on cleansing and disinfection practice of the endoscopes.

Another striking result is that Methicillin resistant S. aureus (MRSA) is the fourth frequent agent isolated. All the four patients with MRSA had no other infection, previous operation or another invasive procedure. As a result, sepsis was accepted ERCP related, having MRSA as causal agent. As the number of staff participating ERCP procedure was low and didn't change for a long time and there was not any cumulation (long time periods in between the cases), the staff was not evaluated in terms of MRSA carrierstate. In future years, during MRSA isolation periods, assessment of the unit staff for the same purpose is planned.
The absence of any fungal agent seems something beneficial, but this might change when the number of the subjects increase.

In the light of these results, the vital role of infection control measures during and after ERCP, that may cause serious complications and mortality, should be emphasized. Main problems mentioned in the literature are inadequate and/or improper cleansing and disinfection (narrow and long tubular structures of the equipment makes it difficult), unsuitable disinfectants and biofilm layer produced by some microorganisms ${ }^{[1-4,8-11]}$. As many institutes in Turkey confront the same issues, we'd like to share our experience (as ICC of Ankara University Hospital). Driven by data obtained, several suggestions have been made to the department. First, the need of adequate room for disinfection of the endoscopes as well as the optimum number of active endoscopes to carry out the daily activity were emphasized ${ }^{[12,13]}$. Among these, following effective mechanical cleansing, immersing the endoscope into $2 \%$ glutaraldehyte solution for 20 minutes to achieve disinfection was stressed ${ }^{[14,15]}$. Besides, endoscopy nurses were educated on preventive measures for glutaraldeyhte toxicity. Secondly, accessories, which do not attract much attention, were mentioned. These are mostly disposable material and if re-usable ones are selected, then they should be sterilized before the procedure. Sterilization of catheters by ethylene oxide and immersion of biopsy forceps into glutaraldehyte solution for a certain time period after effective cleansing were suggested ${ }^{[16]}$. Besides, use of sterile sheets and surgical dressing for every patient were emphasized as "musts". Necessary coordination for these precautions was fulfilled by the ICC.

ERCP / endoscopy units are one of the main institutions to cooperate effectively with ICC's. ICC should observe infection control measures closely, coordinate educational activities and perform periodic microbiological detection with the head of the unit. All the unit staff should try and be willing to be in effective collaboration. The diagnostic and therapeutic advantages of a difficult time and effort-consuming procedure should not be overshadowed by related infections. 


\section{REFERENCES}

1. Nelson, D.B., 2003. Infection control during gastrointestinal endoscopy. J. Lab. Clin. Med., 141: 159-67.

2. Ayliffe, G.A., 1999. Nosocomial infections associated with endoscopy. In: Mayhall C.G. (Ed). Hospital Epidemiology and Infection Control. 2nd Ed. Philadelphia: Lippincott Williams and Willkins, pp: 881-96.

3. Spach, D.H., F.E. Silverstein and W.E. Stamm, 1993. Transmission of infection by gastrointestinal endoscopy and broncoscopy. Ann. Intern. Med., 118: 117-28.

4. Pitted, D., 1997. Nosocomial bloodstream infections. In: Wenzel R.P. (Ed). Prevention and Control of Hospital Infections. Baltimore: Williams-Wilkins, pp: 711-69.

5. Pitted, D., N. Li, R.F. Woolson and R.P. Wenzel, 1997. Microbiological factors influencing the outcome of nosocomial bloodstream infections: A 6-year validated, population-base model. Clin. Infect. Dis., 24: 1068-78.

6. Koneman, E.W., S.D. Allen, W.M. Janda, P.C. Schreckenberger and W.C. Winn, 1997. Diagnostic Microbiology. 5th Ed, Philadelphia: LippincottRaven Publishers.

7. Mollison, L.C., P.V. Desmond and K.A. Stockman, 1994. A prospective study of septic complications of endoscopic retrograde cholangiopancreatography. J. Gastroenterol. Hepatol., 9: 55-9.
8. Novello, P., H. Hagege and M. Ducreux et al., 1993. Septicemias after endoscopic retrograde cholangiopancreatography. Risk factors and antibiotic prophylaxis. Gastroentrol. Clin. Biol., 17: 897-902.

9. Alveyn, C.G., 1993. Antimicrobial prophylaxis during biliary endoscopic procedures. J. Antimicrob. Chemoher., 31(suppl): 101-5.

10. Merighi, A., E. Contato and R. Scagliarini et al., 1996. Quality improvement in gastrointestinal endoscopy: Microbiologic surveillance of disinfection. Gastrointest. Endosc., 43: 457-62.

11. Deva, A.K., K. Vickery and J. Zou et al., 1998. Detection of persistent vegetative bacteria and amplified viral nucleic acid from in-use testing of gastrointestinal endoscopes. J. Hosp. Infect., 39: 149-57.

12. Global consensus conference: Final recommendations. Am. J. Infect. Control, 27: 503-13.

13. American Society for Gastrointestinal Endoscopy. Position Statement: reprocessing of flexible gastrointestinal endoscopes. Gastrointest. Endosc., 43: S41-S46.

14. Fraise, A.P., 1999. Choosing disinfectants. J. Hosp. Infect., 43: 255-64.

15. Rutala, W.A., 1999. Selection and use of disinfectants in healthcare. In: Mayhall C.G. (Ed). Hospital Epidemiology and Infection Control. 2nd Ed. Philadelphia: Lippincott Williams and Willkins, pp: 1161-87.

16. Rutala, W.A., 1996. APIC guideline for election and use of disinfectants. AJIC., 24: 313-42. 